\title{
O Facebook nas Aulas de Espanhol: Uma Experiência de Ensino Híbrido
}

\author{
Marina Soaresl' ${ }^{1}$, Cecilia Aguirre ${ }^{2}$ \\ ${ }^{1}$ Instituto de Letras/ NUPEL - Universidade Federal da Bahia (UFBA) \\ Salvador - BA - Brazil \\ ${ }^{2}$ Instituto de Letras/ NUPEL - Universidade Federal da Bahia (UFBA) \\ Salvador - BA - Brazil \\ marina.asoares@outlook.com; cga.ufba.2015@gmail.com
}

\begin{abstract}
This paper describes a Spanish language teaching experience using Facebook as a complementary learning environment to face-to-face classes, in order to help students develop their speaking and writing skills. It took place at an extension Spanish language course, offered by NUPEL at Instituto de Letras, Universidade Federal da Bahia, Brasil, during semesters 2017.2 e 2018.1, with groups of intermediate and advanced students. Based on the analysis by Moran (2015), Finardi e Porcino (2016), Weissheimer and Leandro (2016) and Mendoza (2018) the experience confirms that facebook is a well-accepted tool capable of enhancing students' collaborative skills and speaking and writing abilities.
\end{abstract}

Resumo. Este artigo descreve uma experiência de ensino de espanhol com o uso do Facebook como ambiente de aprendizagem complementar às aulas presenciais, com o objetivo de incentivar o desenvolvimento da oralidade e da escrita. A experiência foi realizada no NUPEL, curso de extensão de espanhol, oferecido pelo Instituto de Letras, da Universidade Federal da Bahia, durante os semestres 2017.2 e 2018.1, envolvendo alunos de nível intermediário e avançado. Com base nas análises de Moran (2015), Finardi e Porcino (2016), Weissheimer e Leandro (2016) e Mendoza (2018) nossa experiência confirmou o facebook como uma ferramenta de grande aceitação, capaz de incentivar a interação colaborativa e o desenvolvimento da oralidade e da escrita.

\section{Introdução}

A presente experiência foi desenvolvida no contexto formativo do NUPEL, curso de extensão de espanhol oferecido pelo Instituto de Letras da Universidade Federal da Bahia. O curso, de caráter presencial, promove a iniciação à docência dos licenciandos, mediante a oferta para a comunidade externa de aulas de línguas, como Kimbundu e Português, além de Espanhol, Italiano, Francês, Inglês, Alemão, Grego e Latim. O curso de extensão de espanhol, lócus desta experiência, é totalmente presencial.

Nesse contexto, a discussão e planejamento de atividades que envolvem o uso de tecnologias digitais se justifica primeiro, pois uma vez que o professor em formação se encontra imbricado na cultura digital da qual faz parte, (da mesma forma que seus alunos), como produtor e consumidor, ou "prosumidor" (Moran 2015) das múltiplas mídias e linguagens veiculadas pelas tecnologias, entendemos que o processo de formação não 
pode acontecer à margem da sua realidade. Segundo, a proposta se justifica pelo fato de que o projeto pedagógico do curso de Letras ao qual os licenciandos estão vinculados não oferece ainda na sua grade curricular disciplinas que abordem o uso de tecnologias de aprendizagem (Mendoza 2018). Esta carência provoca um hiato, um grave descompasso na formação docente, considerando, sobretudo, que a Base Nacional Comum Curricular, aprovada em 2017, incentiva o trabalho pedagógico com tecnologias já desde os anos iniciais.

Neste sentido concordamos com Vetromille-Castro e Ferreira (2016) em que o projeto político pedagógico dos cursos de licenciatura em Letras deve promover a reflexão sobre o papel das tecnologias de aprendizagem (Mendoza 2018) na prática pedagógica, cumprindo desta forma com seu compromisso social e com a responsabilidade de formar professores críticos, capazes de fomentar a aprendizagem e a construção do conhecimento pela interação entre a universidade e o contexto social e pela inter-relação de novos saberes.

Por outro lado, corroborando com Teles et al (2018), é imperioso que os licenciandos dos cursos de Letras tenham acesso a disciplinas que promovem a discussão e a pesquisa sobre o uso pedagógico de tecnologias digitais, tanto do ponto de vista teórico quanto prático, de forma que tenham a oportunidade de explorar as diversas possibilidades integradoras entre docência e tecnologias.

Assim sendo, os professores em formação do curso de espanhol foram incentivados a experimentar a modalidade de ensino híbrido, entendido neste caso como a utilização de recursos digitais de forma complementar às aulas presenciais. Esta proposta teve o intuito de promover um olhar crítico sobre o uso didático de tecnologias digitais e de discutir quais critérios são relevantes para decidir por uma ou outra ferramenta digital.

As atividades aqui apresentadas foram planejadas pela (na época) professora em formação, uma das autoras deste texto, quem propôs nas turmas dos níveis intermediário e avançado de língua espanhola o uso do Facebook como ambiente de aprendizagem complementar ao livro didático. As atividades objetivam levar os estudantes a produzir textos multimodais, compartilhar e comentar as produções da turma, e interagir em língua espanhola de forma espontânea, natural e prazerosa.

A partir da experiência de semestres anteriores com as turmas do dia sábado, percebemos a necessidade de fazer com que os alunos mantivessem contato com a língua espanhola, uma vez que as responsabilidades e as atividades cotidianas interferiam nos estudos e na realização das tarefas. Consequentemente, delineamos nossa proposta de acordo com as habilidades digitais dos professores e as necessidades e interesses dos seus alunos.

Nas próximas seções, então, relataremos a experiência de ensino na modalidade híbrida realizada com os alunos de nível quatro do curso de extensão de espanhol. Num primeiro momento, abordaremos o conceito de ensino híbrido e seu lugar no processo de ensino e aprendizagem; depois discutiremos a escolha do Facebook como recurso digital para esta modalidade e suas vantagens para o ensino de línguas, e por último, descreveremos a experiência e discutiremos as observações realizadas. 


\section{O hibridismo no processo de ensino e aprendizagem}

Para José Moran (2015) a educação foi sempre híbrida - ou misturada, blended primeiro, pela combinação de diferentes espaços, tempos, atividades, metodologias, públicos; depois pela mobilidade e conectividade oferecida por aparelhos móveis, recursos digitais e internet, tornando-a um processo mais amplo e profundo, mais aberto e criativo.

Para o autor a educação se mostra híbrida de diversas formas, por exemplo, ao integrar várias áreas de conhecimento e de metodologias com atividades, projetos grupais ou individuais, colaborativos e personalizados. Também define como hibrido um currículo flexível, que planeje o que é básico e fundamental para todos e que, ao mesmo tempo, permita caminhos personalizados que atendam as necessidades de cada aluno. Mas, de todos os hibridismos descritos pelo autor, para este trabalho nos interessa aquele que diz respeito às tecnologias híbridas, aquele que integra atividades em sala de aula com as digitais, as presenciais com as virtuais.

A experiência de ensino híbrido proposta aqui encontra embasamento na concepção de ensino e aprendizagem descrita por Moran.

Sobre o ensino, Moran afirma:

O ensino é híbrido porque todos somos aprendizes e mestres, consumidores e produtores de informação e de conhecimento. Passamos, em pouco tempo, de consumidores de grande mídia a "prosumidores" -produtores e consumidores- de múltiplas mídias, plataformas e formatos para acessar informações, publicar nossas histórias, sentimentos, reflexões e visão de mundo. Somos o que escrevemos, o que postamos, o que "curtimos". Nisso expressamos nossa caminhada, nossos valores, visão de mundo, sonhos e limitações. [Moran 2015]

E sobre a aprendizagem:

A aprendizagem se constrói em um processo equilibrado entre a elaboração coletiva - por médio de múltiplas formas de colaboração em diversos grupos - e a personalizada - em que cada um percorre roteiros diferenciadores. A aprendizagem acontece no movimento fluido, constante e intenso entre a comunicação grupal e a pessoal, entre a colaboração com pessoas motivadas e o diálogo de cada um consigo mesmo, com todas as instâncias que o compõem e definem, em uma reelaboração permanente. Em um mundo tão dinâmico, de múltiplas linguagens, telas, grupos e culturas, cada um de nós precisa - junto com todas as interações sociais - encontrar tempo para aprofundar, refletir, reelaborar, produzir e fazer novas sínteses. [Moran 2015]

Concordamos com Moran (2015) em que as metodologias precisam acompanhar os objetivos pretendidos: para promover a participação dos alunos, de forma proativa e espontânea, o professor precisa propor atividades complexas, nas que os alunos devam tomar decisões e avaliar os resultados; para promover sua criatividade, o professor deve oferecer a seus alunos novas possibilidades de mostrar sua iniciativa.

Em decorrência disto, a seguir discutiremos a escolha do Facebook como ambiente de aprendizagem para as aulas de espanhol e suas vantagens, de forma geral, para o ensino de línguas. 


\section{O Facebook como recurso educacional}

Nesse contexto fluido de aprendizagens horizontalizadas, todos somos aprendizes e mestres, ao mesmo tempo consumidores e produtores de informação e de conhecimento. Aprendemos não só nos espaços de educação formal senão em espaços informais também, em um movimento fluido entre a comunicação grupal e a fruição individual, em um diálogo intenso e dinâmico.

A partir dessa realidade, e embora não tenham sido criadas com fins educacionais, as redes sociais adquirem o status de ambiente de aprendizagem, apropriado inclusive para uma proposta híbrida. Neste sentido, vários autores têm discutido as vantagens do Facebook, na perspectiva da aprendizagem de línguas adicionais.

Finardi e Porcino (2016) destacam a socialização, interação e comunicação no processo de ensino e aprendizagem promovidas pelo Facebook. Referenciando os estudos de Llorens e Cadpferro (2011), as autoras descrevem essa rede social como uma ferramenta de aprendizagem colaborativa online já que esta facilita a criação e administração de grupos de trabalho; oferece a possibilidade de bate-papo, a troca de mensagens e a marcação de mensagens e imagens; oferece uma interface de fácil uso e de grande conectividade; e ainda é facilmente adaptável para a aprendizagem móvel.

Por outro lado, referenciando a Allegrette et al (2012), as autoras destacam, entre outras vantagens, a facilidade de conversação que o ambiente do Facebook propicia, a possibilidade de diminuir a hierarquia de poder na relação entre professores e alunos, a possibilidade de quebrar a unidirecionalidade professor-aluno privilegiando assim a interação entre pares e, dessa forma, promovendo uma aprendizagem participativa, a autoria compartilhada e a possibilidade de expansão do ambiente escolar.

Similarmente, para Weissheimer e Leandro (2016) o potencial pedagógico do Facebook se coloca em evidência por se tratar de um espaço altamente interativo, concebido para se conectar socialmente e recuperar laços, onde as pessoas se expressam espontaneamente e criam conhecimento colaborativamente. Para os autores, o ambiente virtual do Facebook resulta menos intimidante que a sala de aula, oferecendo aos alunos flexibilidade, ritmo personalizado para a realização de atividades, e oportunidades profícuas de compreensão e produção oral e escrita.

Por outro lado, na hora de fazer escolhas, a diversidade e multifuncionalidade das tecnologias de aprendizagem constitui o primeiro problema a ser abordado pelo professor. Mendoza (2018) propõe um modelo de análise e seleção de tecnologias a partir de treze parâmetros, dentre os quais destacamos no Facebook: Multimodalidade: permite a elaboração e compartilhamento de textos multimodais; Funcionalidade: criativa, comunicativa e colaborativa; Customização: é customizável pelo professor e pelos alunos; Interatividade: permite a interação entre o usuário e o próprio recurso, professoraluno, aluno-aluno, aluno e o mundo real; Privacidade: é de uso público e privado; Facilidade de uso: é intuitivo; Preço: é gratuito; Compatibilidade: está na rede, IOS e Android; Portabilidade: só requer conexão à internet; Autoria: pertence a uma empresa já consolidada. Concordamos com Mendoza (2018) em que as redes sociais, assim como os recursos digitais de forma geral, não foram criadas expressamente com fins didáticopedagógicos, então é o entorno acadêmico que vai determinar sua otimização didática a fim de propiciar o desenvolvimento das habilidades linguísticas e da competência digital dos estudantes. 


\subsection{Critérios para a escolha do facebook}

As análises e os parâmetros descritos acima definiram o Facebook como um ambiente idôneo para a realização desta experiência de ensino híbrido.

Assim, ele foi escolhido justamente por não se tratar de uma rede social educativa $^{1}$, ou seja, especificamente desenhada para constituir um ambiente de aprendizagem. Dessa forma, o contato dos alunos com as atividades propostas e, portanto, com a língua espanhola seria espontâneo, uma vez que não precisariam acessar um portal ${ }^{2}$ específico de aprendizagem.

Segundo, por ser gratuita e popular, todos os alunos que participaram do projeto já possuíam um perfil nessa rede social.

Terceiro, por ser de fácil acesso, por celulares ou computadores, em formato web ou em aplicativo, não houve queixas com relação à dificuldade de uso.

Quarto, foi escolhida por ser uma plataforma customizável. Utilizamos a opção "grupos", para organizar os alunos de acordo com a sua turma e os configuramos como privados, apenas para uso pela professora e pelos estudantes.

Quinto, porque permite a elaboração e o compartilhamento das produções multimodais dos estudantes. Desde o seu próprio perfil, os discentes compartilhavam os trabalhos no grupo da sala nos prazos estipulados e lá, podiam interagir com os demais colegas.

Sexto, foi escolhida porque permite que o administrador tenha acesso ás interações e visualizações realizadas pelos alunos, o que facilitou seu acompanhamento e avaliação.

Naturalmente, o uso do espanhol era obrigatório, para trabalhos, publicações e comentários. Outro ponto positivo, fundamental para a organização dos professores, é que a data e o horário de todas as postagens ficam visíveis. Por último, cabe salientar como vantagem que o conteúdo postado pode ser revisitado com facilidade pelos alunos.

Em síntese, as funcionalidades do Facebook, brevemente descritas aqui, facilitaram a administração e o desenvolvimento das atividades. $\mathrm{Na}$ próxima seção falaremos sobre o curso de espanhol de forma geral e sobre a experiência didática em particular.

\section{O Facebook nas aulas de espanhol}

O curso de extensão de espanhol, lócus desta experiência, é totalmente presencial. Os horários das aulas estão distribuídos duas vezes por semana de segunda a quinta, ou apenas uma vez, sextas pela noite e sábados. O livro didático utilizado é Aula Internacional, com uma abordagem de ensino orientada à ação, seguindo os descritores de nível do Quadro Comum Europeu de Referência para Línguas ${ }^{3}$. As unidades do livro

\footnotetext{
1 Rede Social Educativa, RSE, por exemplo, Brainly, Leoteca, Otra Educación, Edmodo, Moodle, Blackboard, entre otras.

2 Embora sejam conceitos diferentes, neste trabalho usaremos indistintamente as expressões portal, ambiente, plataforma e rede social.

${ }^{3}$ Disponível em https://www.dge.mec.pt/quadro-europeu-comum-de-referencia-para-linguas
} 
partem da contextualização de conteúdos linguísticos e comunicativos mediante a exposição dos alunos a textos graduados segundo o nível. Essa exposição objetiva o desenvolvimento da compreensão de textos orais e escritos e a apresentação indutiva da gramática. O livro oferece oportunidades de prática linguística e comunicativa variadas, muitas vezes partindo da experiência dos alunos, procurando tornar a observação e percepção do próprio entorno um material de reflexão intercultural e interação comunicativa em sala de aula. A última seção das unidades inclui diversos textos - artigos jornalísticos, textos informativos, letras de canções, fragmentos literários, jogos, e outros - que ampliam a compreensão da realidade cotidiana e cultural dos países de fala hispana.

Entendemos que o livro didático deve ser abordado de forma crítica, questionando se a língua espanhola é apresentada a partir de um discurso hegemônico, homogeneizante e preconceituoso ou se, pelo contrário, o livro didático privilegia a diversidade humana e cultural no mundo hispânico e dá representatividade à cultura própria do público a quem vai dirigido. Assim, a partir dessa observação e das necessidades dos alunos, os professores em formação são orientados a produzir o próprio material e as próprias atividades, fazendo adaptações de acordo com os interesses, caraterísticas e a realidade cultural dos estudantes.

\subsection{Descrição da experiência didática.}

O ponto de partida da experiência foi a análise das necessidades dos alunos. Por terem aula somente aos sábados, observamos que precisavam outras instâncias de contato com a língua espanhola. A ideia da criação de um grupo no Facebook surgiu da necessidade de inserir atividades extras de interação no dia a dia dos estudantes, enquanto estivessem olhando a sua conta, de forma que pudessem relembrar o que aprendemos na aula, mas também produzir sobre o que estudamos. Participando do grupo, ao longo da semana, teriam contato com postagens relacionadas aos assuntos vistos no curso, mas também com outros, como memes, vídeos, músicas e textos do mundo hispânico.

Trabalhamos com o Nível 4 (N4) de espanhol do curso, considerado intermediário ou equivalente ao B2 do Quadro Comum Europeu de Referência para Línguas. Tomando como base o livro Aula Internacional 4, criamos seis atividades para o Facebook, uma para cada unidade do manual. A maioria das postagens dos estudantes tinha como foco a escrita, mas alguns trabalhos também envolviam a produção de vídeos ou fotografias. A parte oral era trabalhada em sala de aula, onde se apresentavam grande parte dos trabalhos postados ou criaram-se grupos de discussão para orientar e organizar a realização das atividades.

Após finalizar um conteúdo ou uma unidade, uma atividade era proposta. Em sala, os alunos recebiam algumas orientações básicas - em que consistia o trabalho, quais seriam os critérios a serem respeitados, quando seria a data limite de entrega/ postagem. Logo, essas orientações, entre outras mais específicas, também eram passadas por e-mail para a turma, momento em que os alunos poderiam tirar possíveis dúvidas.

Geralmente, oferecemos um prazo de até dez dias para a realização do trabalho. Nesse tempo, os estudantes poderiam pesquisar, trocar ideias com os colegas e também solicitar algum auxílio do professor. A maioria dos trabalhos eram individuais. Quando um trabalho em grupo ou dupla era proposto, os alunos contavam com um tempo da aula para se organizar. Ao longo do semestre, estimulamos a criação multimodal, onde textos 
escritos se mesclavam a imagens, vídeos e canções, todos eles produzidos pelos próprios alunos, com os seus próprios recursos - câmera do celular, por exemplo.

As atividades postadas no grupo constituíam um critério de avaliação somativa. Assim, além das notas das provas orais e escritas do curso, os alunos recebiam pontos por sua participação no projeto e pela qualidade do conteúdo que produziam. No entanto, os textos escritos sempre eram corrigidos e entregues aos estudantes. Com isso, incentivamos o aluno a editar a publicação original com as possíveis correções e a refletir sobre os "erros" - geralmente gramaticais -, a fim de não os cometer novamente. Deste modo, acreditamos também ter proporcionado uma avaliação formativa.

Por fim, destacamos que os distintos projetos de aula se basearam nos diferentes gêneros textuais trabalhados no livro didático. Não obstante, entendemos que comunicarse bem numa língua implica saber compreender e produzir seus gêneros em tanto realizações discursivas, pois estes se relacionam diretamente com as práticas sociais exercidas pelo sujeito, segundo aponta Maingueneau (2002 apud Freitas e Vargens 2010). Ensinar o aluno a compreender e produzir esses textos, de acordo com as particularidades do gênero, foi uma das preocupações constantes na seleção das atividades propostas. Porém, não pertence ao escopo deste trabalho abordar a diferença entre gêneros textuais e gêneros discursivos.

\subsection{Descrição das atividades}

Devido ao êxito do projeto no semestre 2017.2, decidimos retomá-lo em 2018.1, ainda com o nível 4. Como trabalhamos com o mesmo livro, mantivemos as mesmas atividades do semestre anterior, porém tentamos otimizá-las, a fim de melhorar a experiência. Posteriormente, comentaremos os pontos positivos e negativos encontrados. Para exemplificar alguns dos trabalhos produzidos pelos alunos, relataremos brevemente duas das atividades propostas no semestre 2017.2 e uma das atividades realizadas em 2018.1.

2017.2 N4 - Gênero "notícia". Unidade 1. Com os alunos, criamos El noticiero de la clase. Os estudantes dividiram-se em grupos ou duplas e cada um deles escolheu uma seção de jornal: Internacional, Nacional, Tecnologia, Economia, Esportes, Cultura, Saúde ou Sociedade. Cada grupo ou dupla deveria escrever uma notícia (real ou fictícia) de acordo com sua seção e publicá-la no grupo, respeitando o uso dos tempos do passado, voz passiva e claro, as características do gênero.

Neste primeiro trabalho, tivemos um momento em sala de aula para apresentar as notícias criadas pelos alunos. Quando realizamos essa discussão, as notícias já estavam postadas no grupo há alguns dias. Observamos que, no geral, os trabalhos foram bem acolhidos pelos colegas, já que todos eles tiveram várias curtidas. No entanto, por ter uma discussão na sala, poucos comentários foram publicados nas postagens dos colegas. Foi interessante perceber que todos os alunos publicaram fotos relacionadas à sua notícia, embora isso não tenha sido solicitado. Assim, as postagens constavam de texto e imagem ilustrativa.

2017.2 N4 - Gênero "guia turístico". Unidade 5. Como atividade de produção grupal, todos os alunos da turma, colaborativamente, construíram um guia turístico da cidade de Salvador. Esse trabalho realizou-se em duas modalidades: oral, mediante visita e gravação de vídeo nos locais preferidos dos alunos, apresentando o local a partir dos seus gostos, hábitos, vínculo com o lugar, história do local apresentado, aspectos relevantes e recomendações; e escrita, a partir da produção de um texto formal, num 
registro culto, sobre o lugar escolhido na primeira fase da atividade. Para finalizar, os alunos procuraram uma música, poema ou texto literário sobre a cidade de Salvador.

As produções dos alunos, nos três momentos da atividade, deviam ser postadas no Facebook. Por se tratar de um projeto em várias etapas, notamos que algumas delas geraram maior repercussão que outras. Os textos formais e cultos foram pouco curtidos e comentados. Por outro lado, os vídeos, as fotografias, os poemas e músicas, no geral, todas as postagens relacionadas diretamente às emoções dos alunos, foram bastante populares. A terceira parte, que pedia a publicação de algum texto literário sobre Salvador foi bem curiosa, já que, espontaneamente, alguns alunos colocaram depoimentos e reflexões justificando a escolha desse poema ou canção. Isso acabou animando os outros, de forma que quase todos os discentes explicaram suas preferências, deixando a postagem muito mais rica.

2018.1 N4 - Gênero "folheto/ panfleto". Gênero oral "seminário". Unidade 4. Os alunos tiveram que escolher, individualmente, uma tribo urbana e pesquisar sobre ela. Em sala, fizeram uma exposição sobre a tribo escolhida - onde surgiu, em que países está presente, como são e quais são as motivações dos seus membros. O estudante poderia trazer recursos - fotos, música, vídeos - para auxiliar a sua apresentação. Durante os seminários, tiramos fotos que logo foram publicadas no grupo.

Como parte escrita, o aluno teria que criar uma espécie de panfleto sobre um paraíso alternativo perfeito para a sua tribo. Deveriam descrever como seriam as cidades, que tipos de pessoas viveriam nela, qual seria o lema do lugar, que tipo de entretenimento teria, entre outros detalhes, de forma a tornar interessante esse local e incentivar a que outros o visitassem. Logicamente, esse "folheto" foi publicado no Facebook.

As atividades dessa unidade foram das mais exitosas no grupo. As fotos das apresentações renderam muitos comentários e curtidas. Os folhetos, que deviam ser inventados, também foram muito lidos. Os alunos abusaram da criatividade para criar essas "cidades". Alguns decidiram desenhar como seria esse lugar, e esse esboço foi compartilhado no grupo. Outros optaram por inovar em suas apresentações, vestindo-se como membros da tribo. Os alunos mais criativos tiveram mais curtidas e comentários nas suas publicações.

Com estes trabalhos, entre outros, os discentes trabalharam os registros coloquial e formal na produção de textos escritos e orais em língua espanhola.

\section{Discussão dos resultados}

As atividades propostas tinham como objetivo possibilitar que o aluno colocasse em prática as competências adquiridas nas unidades recém trabalhadas e também utilizasse todo o conhecimento obtido na sua trajetória como aluno de espanhol. Em termos de aprendizagem, acreditamos ter colhido resultados muito positivos, pois a elaboração desses trabalhos, muitos deles em várias etapas, envolvia estudo do conteúdo, análise de possibilidades, escrita criativa e reescrita com correção gramatical. Assim, consideramos ter reafirmado a aprendizagem em sala de aula, pré-requisito para os níveis superiores. Graças aos projetos, o aluno adquiriu competência para produzir textos orais e escritos, de diversos gêneros, em registro formal e informal, a cada instancia de prática. Com o tempo, os estudantes melhoraram significativamente o modo como se expressavam em língua espanhola. 
Inicialmente, acreditamos que a experiência seria melhor realizada em grupos de nível intermediário e avançado (no curso, níveis 4, 5 e 6), pois o aluno já teria um bom domínio do idioma e os gêneros trabalhados e publicados não teriam que ser graduados segundo a sua dificuldade. Nos níveis mais básicos (no curso, níveis 1,2 e 3), que não participaram da experiência, as produções escritas e orais também foram realizadas. No entanto, nem sempre podiam ser compartilhadas com a turma por questões de local, tempo ou calendário.

Desta forma, observamos que o compartilhamento no Facebook dos trabalhos realizados, disponíveis online a qualquer momento, incentivou a curiosidade e a criatividade dos alunos. Cientes de que seus trabalhos seriam vistos e comentados pelos colegas da própria ou de outras turmas participantes, observamos que os alunos foram melhorando a qualidade das produções, cada vez mais criativas, mais apelativas e melhor organizadas, marcando a diferença com respeito àqueles alunos que não participaram desta experiência.

Refletindo sobre a escolha das turmas, hoje estenderíamos o uso do Facebook também aos níveis iniciais. Assim, a modalidade de ensino híbrido, que se revelou tão produtiva, acompanharia toda a trajetória do aluno no aprendizado da língua espanhola, formando discentes mais hábeis nas expressões escrita e oral.

Embora o objetivo principal do grupo era compartilhar e comentar os trabalhos de sala, muitos alunos começaram a postar outros assuntos: testes no buzzfeed, vídeos engraçados, memes, músicas e a comentar sobre eles, espontaneamente e em espanhol. $\mathrm{O}$ sucesso das postagens dos colegas resultou um incentivo à criatividade e participação.

Cabe ressaltar que todas as curtidas e comentários eram feitos de forma espontânea, pois não constituíam um critério avaliativo. Porém, essa interação espontânea nem sempre foi produtiva, pois observamos que os alunos mais simpáticos e populares recebiam muitas curtidas e comentários, enquanto outros, muitas vezes, tinham poucas interações, ou nulas, desestimulando sua produção. Por este motivo, acreditamos que seria interessante que o projeto incluísse a necessidade de comentar nas publicações dos colegas, de modo a incentivar e valorizar a todos da mesma forma.

De modo geral, os alunos expressaram sua satisfação com o conteúdo produzido durante o período, já que os semestres realmente foram árduos e proveitosos. Ao combinar os prazos das publicações, ouvir as sugestões dos estudantes e claro, colocá-las em prática, sentimos que todos ficaram conformes e o trabalho com a rede foi compatível com as possibilidades e a rotina dos estudantes. Ao ver-se incluídos e respeitados, todos participaram com seriedade e esmero.

\section{Considerações finais}

Como conclusão, podemos afirmar que a proposta de experimentar a modalidade de ensino híbrido de forma complementar às aulas presenciais de espanhol foi duplamente exitosa: em primeiro lugar, porque a discussão entre os professores em formação sobre o uso didático de tecnologias digitais resultou em ricas trocas e planos de aula criativos, como o exemplo aqui descrito; em segundo lugar, no que tange a esta experiência em particular, porque os objetivos de produzir textos multimodais, compartilhar e comentar as produções dos colegas e interagir em língua espanhola de forma espontânea, natural e prazerosa foram atingidos a contento. Prova disto é a confirmação de que os estudantes melhoraram significativamente a produção escrita e oral em língua espanhola, em 
comparação com aquelas turmas que não participaram da experiência, e sobretudo pela satisfação, expressamente manifesta pelos alunos, com o trabalho realizado.

Por último, esta experiência envolveu apenas as turmas dos níveis intermediário e avançado, porém consideramos que as turmas dos níveis iniciais também devem ser envolvidas para oferecer as propiciações do ensino híbrido durante toda a trajetória do aluno. Ainda, pretendemos nos aprofundar no estudo de metodologias ativas como embasamento do trabalho em sala, metodologias tais como sala de aula invertida ou pedagogia por projetos, específicas para a modalidade híbrida de ensino.

\section{Referências}

Corpas, Jaime; García, Eva; Garmendia, Agustín, Soriano, Carmen. (2014) Aula Internacional 4, Curso de espanhol, Barcelona, Editora Difusión.

Finardi, Kyria; Porcino, Maria Carolina. (2016) "Facebook na ensinagem de inglês como língua adicional", In: Redes sociais e ensino de línguas: o que temos que aprender? Organizado por Júlio Araújo e Vilson Leffa, São Paulo, Parábola Editorial, p. 92-109.

Mayrink, Monica; Costa, Heloisa. (2017) "Caminhos investigativos na articulação entre ensino de línguas e virtualidade: reflexões para a elaboração de programas de formação de professores", In: Tecnologias digitais no ensino de línguas e na formação de professores: reorganizando sistemas educacionais, organizado por Michele El Kadri, Denise Ortenzi e Samantha Ramos, Campinas, SP, Pontes Editora, p.151-168

Moran, José. (2015) "Educação híbrida: um conceito chave para a educação, hoje”, In: Ensino híbrido: personalização e tecnologia na educação [recurso eletrônico] Organizado por Lilian Bacich, Adolfo Tanzi Neto e Fernando de Mello Trevisani, Porto Alegre, Penso, e-pub.

Román Mendoza, Esperanza. (2018) Aprender a aprender en la era digital. Tecnopedagogía crítica para la enseñanza del español LE/L2, [Recurso eletrônico] New York, Routledge, e-pub.

Teles, Gabriela, et.al. (2018) "Docência e Tecnologias Digitais da Informação e Comunicação: Matrizes Curriculares das Licenciaturas" Anais... III Congresso sobre Tecnologias na Educação, Cultura Maker na Escola, Fortaleza, Ceará, Brasil, 5 a 8 de junho de 2018, http://ceur-ws.org/Vol-2185/CtrlE_2018_paper_12.pdf.

Vargens, Dayala; Freitas, Luciana. (2010) “Ler e escrever. Muito mais que unir palavras", In: Espanhol: ensino médio, Barros, C.S. de Goettenauer, Elzimar de Marins Costa (Coord.), Brasília: Ministério da Educação, Secretaria de Educação Básica, Coleção Explorando o Ensino, [online] http://portal.mec.gov.br/docman/abril-2011-pdf/78362011-espanhol-capa-pdf/file.

Vetromille-Castro, Rafael; Simões Ferreira, Kathleen. (2016) "Redes sociais na formação de professores de línguas", In: Redes sociais e ensino de línguas: o que temos que aprender? Organizado por Júlio Araújo e Vilson Leffa, São Paulo, Parábola Editorial, p. $155-170$.

Weissheimer, Janaína; Leandro, Diêgo Cesar. (2016) "Facebook e aprendizagem híbrida de inglês na universidade", In: Redes sociais e ensino de línguas: o que temos que aprender? Organizado por Júlio Araújo e Vilson Leffa, São Paulo, Parábola editorial, p. 123-136. 